Review Article

\title{
Guidelines for the endoscopic nasal surgery during COVID-19 pandemic
}

\author{
Parvez Husain $^{1 *}$, Shaheen Khalil Ahmed ${ }^{2}$, Benazeer Husain ${ }^{3}$
}

${ }^{1}$ Department of ENT, Expert ENT and Diagnostic Centre, Barabanki, Uttar Pradesh, India

${ }^{2}$ Department of Anaesthesia, Expert ENT and Diagnostic Centre, Barabanki, Uttar Pradesh, India

${ }^{3}$ Department of Oral Pathology, Expert ENT and Diagnostic Centre, Barabanki, Uttar Pradesh, India

Received: 01 September 2020

Revised: 31 October 2020

Accepted: 31 October 2020

\section{*Correspondence: \\ Dr. Parvez Husain, \\ E-mail: parvez.talkme@gmail.com}

Copyright: $\odot$ the author(s), publisher and licensee Medip Academy. This is an open-access article distributed under the terms of the Creative Commons Attribution Non-Commercial License, which permits unrestricted non-commercial use, distribution, and reproduction in any medium, provided the original work is properly cited.

\section{ABSTRACT}

COVID-19, the respiratory illness caused by the novel SARS-CoV-2 virus has rapidly emerged as a serious global health concern. The world health organization (WHO) and has enacted various protocols for healthcare institutions internationally in an attempt to slow the spread of disease, including adjustments for procedures performed by otolaryngologists. Based upon published evidence we highlight different strategies to reduce infection transmission during endoscopic sinus surgery. All patients undergoing endoscopic sinus surgery should be discussed with health care staff to be involved in procedure. The patients should be divided into elective, semi-elective, and urgent/emergency. COVID-19 test should be done in all patients prior to surgery along with high resolution computed tomography (HRCT) chest. Irrespective of COVID screening results, it is advisable to treat all patients undergoing aerosol generating procedures as COVID-19 positive, and the whole theatre team should wear personal protection equipment (PPE) as per current national guidelines. Preoperative nasal decongestion to be undertaken with atomization devices. Consider telephone/video clinic follow up appointments unless clinical examination is considered essential. Considering the current health crisis caused by COVID-19, the following guidelines are recommended for performing nasal surgeries: patient visits must be limited to only urgent/emergent cases for the time being. Only vital personnel should remain in the OT while performing any nasal endoscopic procedure as this will both reduce exposure and conserve vital personal protective equipment. Five levels of protection are recommended for the person performing the procedure.

Keywords: COVID-19, Endoscopic, Nasal surgery, Pandemic

\section{INTRODUCTION}

COVID-19, the respiratory illness caused by the novel SARS-CoV-2 virus has rapidly emerged as a serious global health concern. As of March 12, 2020, the WHO has declared this virus a pandemic. ${ }^{1}$ Coronavirus causes respiratory tract infections the severity can be mild, like common cold, and can be even lethal, like SARS (severe acute respiratory syndrome), MERS (middle east respiratory syndrome), and COVID-19 (corona virus disease 2019). COVID-19 disease was first identified in
December 2019 in Wuhan, the capital of China's Hubei province and it caused a pandemic. ${ }^{2}$ The WHO has enacted various protocols for healthcare institutions internationally in an attempt to slow the spread of disease, including adjustments for procedures performed by otolaryngologists. ${ }^{3}$

Research shows that there is a high viral load in the nasopharyngeal area. ${ }^{4}$ This makes managing patients with pathologies that require endoscopic sinus surgery to be a major concern especially with the use of microdebriders 
and drills in these surgeries causing aerosolization of COVID-19. Bioaerosol transmission occurs while doing intubation and cardiopulmonary resuscitation. Fomite transmission is also possible. The virus is most contagious when people are asymptomatic: although spread can occur even before symptoms appear. Airborne transmission of SARS-CoV-2 can occur during medical procedures that generate aerosols ("aerosol generating procedures"). ${ }^{5}$

SARS-CoV-2 can remain viable and infectious in aerosols for hours, and on surfaces up to days; the median half-life of SARS-CoV-2 was approximately 1.1 hour in aerosols, 5.6 hours on stainless steel and 6.8 hours on plastic; no viable virus was measured on cardboard after 24 hours, but virus was still detectable (depending on the inoculum shed) on plastic and stainless steel after $72 \mathrm{~h}$ aerosol and fomite transmission of SARS-CoV-2 is plausible, since the virus can remain viable and infectious in aerosols for hours and on surfaces up to days (depending on the inoculum shed). ${ }^{6}$ The healthcare workers involved in its management like otorhinolaryngologists, dentists, head-neck surgeons, gastroenterologists, pulmonologists, speech therapists or ophthalmologists are most prone to infection with a risk ratio of $2.13 .^{7,8}$ Hence It mandates the need of adequate preventive measures for such healthcare workers. ${ }^{9}$

Keeping all this in mind the procedures which need instrumentation of upper airway should be done only in cases of emergency or if absolutely necessary, COVID19 testing should be given importance. Otorhinolaryngologists should be aware of utmost importance of effective use of full or enhanced PPE during diagnostic and therapeutic procedures dealing the nasal and aero-digestive tract. Enhanced PPE includes N95 mask with a face shield or powered air-purifying respirator (PAPR), surgical cap, surgical gown and double gloves.

\section{METHODS}

Nasal pathologies are usually detected earlier due to varying symptoms and with treatment most cases get well soon. But in this COVID-19 era there is more chance that patient with mild nasal symptoms stay at home and the disease can progress to a severe or may be lifethreatening condition. As a dictum most of the nasal procedure should be deferred during this COVID-19 pandemic and only emergency cases need to be assessed and operated by following the protocol and keeping them in mind.

Based upon published evidence we highlight different strategies to reduce infection transmission during endoscopic sinus surgery.

\section{Case selection}

All patients undergoing endoscopic sinus surgery should be discussed with the assisting surgeon, anaesthetist, scrub nurse and other health care staff and should be divided into: elective, semi-elective, urgent/emergency surgery. If delaying surgery is unlikely to cause harm then review every 3 months or sooner if the patient develops any change in symptoms. For patients in whom surgery cannot be deferred, the following precautions/ modifications should be considered:

\section{Pre-operative}

Test should be done of all potential admissions for COVID-19. The patients must have self-isolate themselves for at least seven days before admission. ${ }^{10,11}$ Patients who have no symptoms suggestive of COVID-19 infection, have been isolated for seven days and have a negative COVID-19 test should be admitted to a COVID free facility (ward) and operated on in a COVID free theatre. After seven days of isolation patient is admitted 48 hours prior to surgery. The second test is done at the time of admission, if the test is negative HRCT of chest is done to exclude any false negative test result. HRCT chest positive findings included ground-glass opacity, local patchy shadowing, bilateral patchy shadowing, or interstitial abnormalities.

As PCR testing may only be around $75 \%$ sensitive the theatre team should still wear full PPE as for COVID positive patients as all these procedures are aerosol generating. ${ }^{11}$

Patients who are COVID-19 positive should be admitted to a COVID facility and operated on in a COVID theatre wearing full PPE as all these procedures are aerosol generating. ${ }^{11}$

\section{Day of surgery}

Irrespective of the PCR test results all the operation theatre (OT) staff should wear full or enhanced PPE which includes N95 mask with a face shield or PAPR, surgical cap, surgical gown and double gloves. OT staff should be pre-assigned and once entered into the OT with enhanced PPE should not leave the room till the procedure ends or due to some special circumstances. Also, the staff outside the OT should not enter the OT.

\section{Patient preparation}

Gargling with povidone-iodine (at a concentration of $0.23-1 \%$ ) for 1 minute $1-2$ hours prior to surgery will reduce the viral load in the pharynx by at least $4 \times \log 10$ (corresponding to a reduction in viral titre of $\geq 99.99 \%$ for all coronaviruses tested. ${ }^{12,13}$ Povidone iodine, has been used as a gargle for mucositis and nasal rinse for recalcitrant sinusitis with no negative effect on olfaction, mucociliary clearance and improvement in mucositis. ${ }^{14-16}$ If the patient is iodine intolerant then we would suggest $0.5 \%$ hydrogen peroxide. ${ }^{17}$ 
Irrespective of COVID screening results, it is advisable to treat all patients undergoing aerosol generating procedures as COVID-19 positive, and the whole theatre team should wear PPE as per current national guidelines. ${ }^{11}$

Induction of anaesthesia and intubation to be done in theatre and not in anaesthetic room to minimise potential contamination. While intubating the patient the surgical team should wait outside the operation theatre, postintubation for 21 minutes. ${ }^{18}$

After draping the patients, first layer with the plastic drapes and second by linen, endoscopes and camera should also be draped in a similar pattern.

Preoperative nasal decongestion to be undertaken with atomization devices e.g. MADgic ${ }^{\circledR}$ laryngotracheal mucosal atomisation device, rather than nasal packing to reduce aerosol generation.

Throat pack removal is aerosol generating and, therefore, recommend not using throat packs where it is safe to do so.

Nasal irrigation with povidone-iodine (0.23-1\%) antiseptic for 1 minute at start of surgery. ${ }^{12,13,19}$ Avoid nasal packing and or internal nasal splints/stents unless absolutely necessary as pack removal will be aerosol generating. Absorbable nasal packs should be used wherever possible. Theatre cleaning should be undertaken. $^{20}$

\section{Postoperative period}

After surgery, first the endoscope drape is removed and then the patient drape is removed in layers preventing any spillage and drape is carefully rolled and removed. Thereafter patient is cleaned and anaesthetist extubates the patient while surgical team waits outside the operation theatre post-extubation for 21 minutes. ${ }^{18}$

Minimise the post-operative stay to reduce the risk of hospital acquired COVID. ${ }^{21}$

Consider telephone/video clinic follow up appointments unless clinical examination is considered essential.

All the elective routine surgeries are deferred till the COVID-19 pandemic gets over. If the surgery is posted then the patient and family members are asked to selfquarantine till the surgery. If the tests are negative then COVID-19 protocol is followed. If the tests are positive, then it is better to defer the case and try alternative treatment unless and until it is a life-threatening condition.

\section{DISCUSSION}

COVID-19 is a pandemic and health care staff and otorhinolaryngologist are at high risk of getting infected. Although many surgical cases are deferred, still crucial life-threatening cases need to get operated.

Nasal endoscopy and nasal surgery remain one of the most commonly performed procedures in otolaryngology. ${ }^{22}$ However, given the concerns mentioned previously, in this time of COVID-19, indications to perform nasal surgery should be judiciously weighed against the potential risks. As of March 18, 2020, the centres for Medicare and medical aid services (CMS) has limited "all non-essential planned surgeries and procedures, including dental, until further notice". Only procedures/surgeries in a high acuity situation or in unstable patients should continue. ${ }^{23}$

Based on the surgeon general's advice, all elective procedures should be currently halted. Nasal surgeries at this point should only be considered for emergent/urgent cases. In the minority of cases where nasal surgery cannot be avoided, a protocol should be followed i.e. COVID-19 test, HRCT chest, and wearing full or enhanced PPE during diagnostic and therapeutic procedures dealing the nasal and aero-digestive tract.

\section{CONCLUSION}

Considering the current health crisis caused by COVID19, the following guidelines are recommended for performing nasal surgeries: Patient visits must be limited to only urgent/emergent cases for the time being. Only vital personnel should remain in the OT while performing any nasal endoscopic procedure as this will both reduce exposure and conserve vital personal protective equipment. Five levels of protection are recommended for the person performing the procedure: N95 mask with a face shield or powered air-purifying respirator (preferred), eye protection (goggles), surgical cap, surgical gown and double gloves. Use atomization devices in place of nasal packs and aerosol generating decongestants and anaesthetics. In addition, protocol of COVID-19 testing; isolation; testing; HRCT should be followed prior to emergent surgeries, with the expectation that the surgery for patients who test positive will be postponed unless the patient is having life-threatening condition. Finally, all non-essential personnel should be limited during any emergent ENT surgeries along with proper patient preparation.

Funding: No funding sources

Conflict of interest: None declared

Ethical approval: Not required

\section{REFERENCES}

1. WHO. WHO Director-General's Opening Remarks at the Media Briefing on COVID-19. 2020. Available 
at: www.who.int/dg/speeches/detail/who-directorgeneral-s-opening-remarks-at-the-media-briefing-oncovid-19---11-march-2020. Accessed on 02 August 2020.

2. Hui DS, Azhar IE, Madani TA, Ntoumi F, Kock R, Dar O. The continuing 2019-nCoV epidemic threat of novel coronaviruses to global health-the latest 2019 novel coronavirus outbreak in Wuhan, China. Int J Infect Dis. 2020;91:264-6.

3. WHO. 2020. Operational Planning Guidelines to Support Country Preparedness and Response. Available at: www.euro.who.int/en/healthtopics/health-emergencies/coronavirus-covid19/training-courses. Accessed on 02 August 2020.

4. Zou L, Ruan F, Huang M, Liang L, Huang H, Hong $Z$ et al. SARS-CoV-2 Viral Load in Upper Respiratory Specimens of Infected Patients. N Eng J Med. 2020;382(12):1177-9.

5. Advice on the use of masks in the context of COVID-19. Interim guidance. Geneva: World Health Organization. 2020. Available at: https://www.who. int/publications/i/item/advice-on-the-use-of-masksin-the-community-during-home-care-and-inhealthcare-settings-in-the-context-of-the-novelcoronavirus-(2019-ncov)-outbreak). Accessed on 02 August 2020.

6. Van Doremalen $\mathrm{N}$, Bushmaker $\mathrm{T}$, Morris $\mathrm{DH}$, Holbrook MG, Gamble A, Williamson BN. Aerosol and surface stability of SARS-CoV-2 as compared with SARS-CoV-1. N Engl J Med. 2020;382:1564-7.

7. Meng L, Hua F, Bian Z. Coronavirus disease 2019 (COVID-19): emerging and future challenges for dental and oral medicine. J Dent Res. 2020;99(5):481-7.

8. Lai THT, Tang EWH, Chau SKY, Fung KSC, Li $\mathrm{KKW}$. Stepping up infection control measures in ophthalmology during the novel coronavirus outbreak: an experience from Hong Kong. Graefes Arch Clin Exp Ophthalmol. 2020;3:1-7.

9. Lu D, Wang H, Yu R, Yang H, Zhao Y. Integrated infection control strategy to minimize nosocomial infection of coronavirus disease 2019 among ENT healthcare workers. J Hosp Infect. 2020;104(4):4545.

10. Specialty guide Essential Cancer surgery and coronavirus. Available at: https://www.england. nhs.uk/coronavirus/wp-content/uploads/sites/52/2020 /04/C0239-Specialty-guide-Essential-Cancer-surgery -and-coronavirus-v1-70420.pdf 5. Accessed on 02 August 2020.

11. Wuhan novel corona virus infection prevention and control. Available at: https://www.gov.uk/ government/publications/wuhan-novel-coronavirusinfectionprevention-and-control. Accessed on 02 August 2020.

12. Geller C, Varbanov M, Duval RE. Human coronaviruses: insights into environmental resistance and its influence on the development of new antiseptic strategies. Viruses. 2012;4:3044e68.

13. Eggers M, Koburger-Janssen T, Eickmann M, Zorn J. In Vitro Bactericidal and Virucidal Efficacy of Povidone-Iodine Gargle/Mouthwash Against Respiratory and Oral Tract Pathogens. Infect Dis Ther. 2018;7(2):249-59.

14. Kanagalingam J, Chopra A, Hong M, Ibrahim W, Villalon A, Lin J. Povidone-iodine for the management of oral mucositis during cancer therapy. Oncol Reviews. 2017;11(2).

15. Panchmatia R, Payandeh J, Al-Salman R, Kakande E, Habib A, Mullings W et al. The efficacy of diluted topical povidone-iodine rinses in the management of recalcitrant chronic rhinosinusitis: a prospective cohort study. Eur Arch Oto-Rhino-Laryngol. 2019;276(12):3373-81.

16. Rezapoor M, Nicholson T, Tabatabaee R, Chen A, Maltenfort M, Parvizi J. PovidoneIodine-Based Solutions for Decolonization of Nasal Staphylococcus aureus: A Randomized, Prospective, Placebo-Controlled Study. J Arthroplasty. 2017;32(9):2815-9.

17. Kampf G, Todt D, Pfaender S, Steinmann E. Persistence of coronaviruses on inanimate surfaces and their inactivation with biocidal agents. J Hospital Infect. 2020;104(3):246-51.

18. Appendix B. Air guidelines for environmental infection control in health-care facilities (2003), US, HHS. Available at: https://www.cdc.gov/infection control/guidelines/environmental/appendix/air.html. Assessed on: 20 April 2020.

19. Kariwa H, Fujii N, Takashima I. Inactivation of SARS coronavirus by means of povidone-iodine, physical conditions and chemical reagents. Dermatol (Basel). 2006;212(1):119-23.

20. British Standard Institution. Specification for The Planning, Application, Measurement and Review of Cleanliness Services In Hospitals. London: BSI. 2014.

21. Rajan N, Joshi GP. The COVID-19: Role of Ambulatory Surgery Facilities in This Global Pandemic. Anesth Analg. 2020;131(1):31-6.

22. Alvi S, Harsha P. Flexible Nasopharyngoscopy. StatPearls Publishing. 2020.

23. Services Cf MM CMS Adult Elective Surgery and Procedures Recommendations. 2020. Available at: http://cqcounter.com/whois/domain/cfmm.com.html. Accessed on 02 August 2020.

Cite this article as: Husain P, Ahmed SK, Husain B. Guidelines for the endoscopic nasal surgery during COVID-19 pandemic. Int J Otorhinolaryngol Head Neck Surg 2020;6:2334-7. 